\title{
Intron retention in Cathelicidin-4 in river buffalo
}

\author{
Ahlam A. Abou Mossallam*, Soheir M. El Nahas, Esraa A. Balabel, El Hassan T. Shahwan and Noha M. Osman
}

\begin{abstract}
Background: The function of cathelicidins-4 (CATH4) is not limited to microbial killing, but extends to other aspects of immunity and tissue repair. The presence of different CATH4 variants including intron retention affects the immunity system. Intron retention, in buffalo, is not fully studied. In this study, we investigated CATH4 mRNA in river buffalo and their variants, which can be used in the future for selecting buffalo resistant to diseases.

Results and conclusion: Analysis of CATH4 mRNA in river buffalo (Egyptian breed) revealed the presence of a novel variant (1073 bp) which includes unspliced part of intron 3 (469 bp) in addition to previously reported unspliced complete intron 1 (103) and intron 2 (137 bp). Identification of intron retention was conducted by comparing the amplified unspliced cDNA and DNA sequences. Analysis of the 3 retained intronic regions revealed the presence of the 4 splice signals, needed for splicing which include the $5^{\prime}(\mathrm{GT})$ and $3^{\prime}$ (AG) intron splice sites, the branch point, and the polypyrimidine tract. However, in the intron-retained sequence, the polypyrimidine tract was weak. It contained 6 and 4 non-continuous uridine stretch in introns 1 and 2, respectively, (intron 3 was partial) which may have caused introns retention. In addition, analysis of the unspliced sequence showed three unique exonic SNPS located close to the splice sites (1 to 22 nucleotides) and five SNPs in retained intronic regions located near the splice sites (18 to 246 nucleotides away from exon/intron boundaries) which may be related to the retention of the three introns.
\end{abstract}

Keywords: Egyptian buffalo, Cathelicidine-4, CATH4 splice sites, cDNA, SNPs

\section{Background}

Cathelicidin-4 (CATH4), popularly known as indolicidin, has broad and rapid microbicidal effect that may be critically important to clear tissues from pathogens and to prevent the onset of infection (Dorschner et al. 2001). The function of cathelicidins is not limited to microbial killing, but extends to other aspects of immunity and tissue repair (Gallo et al. 2002). CATH4 contains 4 exons and 3 introns: the first 3 exons comprise signal peptide and cathelin prodomain ( $\mathrm{N}$-terminal) while the fourth exon encodes the cleavage site and variable $\mathrm{C}$-terminal antimicrobial peptide (Zanetti et al. 2000; Zaiou and Gallo 2002).

Water buffalo (Bubalis bubalis) population includes river (Bubalus bubalis bubalis) and swamp buffalo (Bubalus bubalis carabanesis), 77\% of which are river buffalo (FAO, 2013). Buffalo are major source of meat, milk, and its biproducts. Buffalo surpass the cattle in its ability to adapt to the hot, humid areas of muddy and swampy lands (Marai

\footnotetext{
* Correspondence: ahlammasry@yahoo.com

Cell Biology Department, Genetic Engineering and Biotechnology Division, National Research Centre, Dokki, Cairo 11622, Egypt
}

and Habeeb 2010). Buffalo CATH4 was cloned by Das et al. (2006). The complete CATH4 coding region was found to be 92.9\% similar to Bos taurus nucleotide sequence. Several cathelicidin genes were identified in cattle and buffaloes. In cattle, SNPs, insertions, and deletions have been reported in different breeds of Bos taurus and Bos indicus (Gillenwaters et al. 2009). In a study by Brahma et al. (2015), amplicons of cathelicidin genes of 5 breeds of cattle and buffalo were investigated. Buffalo CATH4 genes showed higher single-nucleotide variations compared to cattle genes.

Constitutive splicing of intronic sequences from RNA is the dominant form of gene expression. However, alternative splicing leading to intron retention (IR) has been reported in many bovine genes (Chacko and Ranganathan 2009). Examples of IR have been found in bovine growth hormone (Dirksen et al. 1995), CD46 (Wang et al. 2014), and NCF4 (Ju et al. 2015). A higher relative frequency of IR has been associated with genes with overall shorter intron lengths ( 100-200 nt), higher expression levels, weaker splice sites, and particular densities of Cis-regulatory elements (Sakabe and de Souza 2007). Recent evidences suggest that single- 
Table 1 Sequences of primer pairs used

\begin{tabular}{|c|c|c|c|c|c|}
\hline Primer number & CATH4 & 5'-sequence-3' & Target length & Annealing temp. & Accession no. \\
\hline \multirow[t]{2}{*}{1} & $\mathrm{~F}$ & CATGCAGACCCAGAGGGCCA & $502 \mathrm{bp}$ & $62^{\circ} \mathrm{C}$ & gb|EF050453.1| \\
\hline & $\mathrm{R}$ & ATCAGACACTTAGGACTCTTCCCCG & & & \\
\hline \multirow[t]{2}{*}{2} & $\mathrm{~F}$ & GGGCCATCCTCTCGTTGG & $607 \mathrm{bp}$ & $54^{\circ} \mathrm{C}$ & XM_006065186.1 \\
\hline & R & GGAGCATGTGGTTGAATC & & & \\
\hline
\end{tabular}

nucleotide polymorphisms (SNPs) are the main factor that contribute to the generation of alternative splice variants, which can cause degenerative axonopathy (Drögemüller et al. 2011) and a congenital mechanobullous skin disorder (Menoud et al. 2012) in cattle.

In this study, we investigated the different splice variants of mRNA CATH4 in river buffalo (Egyptian breed) which can be used for selecting disease-resistant breeds of buffalo.

\section{Materials and methods}

\section{Collecting buffalo samples}

Blood samples collected on ethylene diamine tetra acetic acid (EDTA) from healthy river buffalo (Egyptian breed) were kindly provided by the veterinarian of the buffalo farm "United Farms Group Company."

\section{DNA extraction}

Genomic DNA was extracted from whole blood using salting out method according to Miller et al. (1988). The DNA concentrations were measured using Nanodrop 1000 (Thermoscientific) and were adjusted to $50 \mathrm{ng} / \mu \mathrm{L}$ for polymerase chain reaction (PCR).

\section{3. mRNA extraction and CDNA synthesis}

Total RNA from blood was extracted using Easy-RED ${ }^{\text {тм }}$ iNtRON Biotechnology, Inc. according to the manufacturer's instructions. RNA was considered to be free of DNA and proteins with a 260/280 optical density ratio of $\sim 2.0$. cDNA synthesis was performed using Revert Aid First Strand Synthesis Kit according to the manufacturer's instructions. To ensure that the RNA was not contaminated with genomic DNA, a PCR reaction was performed using RNA in absence of reverse transcriptase, as a negative control.

\section{Primers design}

Two primer pairs were designed to investigate CATH4 in Egyptian buffalo, using Primer3 software (Untergasser and Cutcutache, 2012). Table 1 presents the primer pair sequences and the accession number from which they were designed.

\section{PCR amplification}

PCR amplification for CATH4 was performed in $50 \mu \mathrm{l}$ reaction volume which includes $20 \mu \mathrm{l}$ of water (nucleasefree), $25 \mu \mathrm{l}$ of PCR Master Mix (2X), $1 \mu \mathrm{l}$ of forward primer $(10 \mu \mathrm{M}), 1 \mu \mathrm{l}$ of reverse primers $(10 \mu \mathrm{M})$, and $4 \mu \mathrm{l}$ of $50 \mathrm{ng}$ of DNA or cDNA template. The reaction mixture was run in a Q-Cycler, HVD LifeSciences. The thermal cycling program was initial denaturation at $95^{\circ} \mathrm{C}$ for 3 min followed by 40 cycles of the following: denaturation at $95^{\circ} \mathrm{C}$ for 30 s, annealing for $30 \mathrm{~s}\left(54^{\circ} \mathrm{C}\right.$ or $\left.62^{\circ} \mathrm{C}\right)$, extension at $75^{\circ} \mathrm{C}$ for $1 \mathrm{~min}$, and then final extension at $75^{\circ} \mathrm{C}$ for 10 min. Detection of PCR products were performed by agarose gel electrophoresis according to the method described by Ausubel et al. (1990). The gels were inspected by Gel documentation system (In Genius, Syngenebioimaging). PCR products were purified using MEGAquick-spin ${ }^{\text {TM }}$ Total Fragment DNA Purification Kit (iNtRON biotechnology) according to the kit's instructions.

\section{Sequence analysis and SNPs identification}

Purified PCR products were sequenced by Macrogen (Korea) using reverse and forward primers. The specificity of the nucleotide sequences were verified by BLAST analysis (Basic Local Alignment Search Tool) (http://blast.ncbi. nlm.nih.gov/Blast.cgi) (Altschul et al. 1990). Sequences

ATGCAGACCCAGAGGGCCATCCTCKYGTTGGGGCGGTGGTCACYGTGGCTTCTGCTGCTGGGGCTTG TGGTGTCCTCGACCAGYGCCCAGGACCTCAGCTACAGGGARGCCGTGCTTCGTGCTGTGGATCAGCT CAATGAGCGGTCYTCAGAAGCTAATCTCTACCGCCTCCTGGAGCTAGAMCCRCCTCCCAAGGATGAT GCAGATCTGGGCACTCGAAAGCCTGTGAGCTTCACGGTGAAGGAGACTGTGTGCCCCAGGACGAC TCAGCAGCCYRCGGAGCRGTGTGACTTCAAGGAGGAAGGGCGGGTGAARCAGTGTGTGGGGACA GTCACCCTGGACCCGTCCAATGACCAGTTTGACCTAAACTGTAATGAGCTCCAGAGTGTCAGGATAC GCTTTCCATGGCCATGGCCATGGCCATGGTGGCGCAGATTCCGAGGTTGATGGACAAGAACTGTTG GATCCCRAGCCCGGGGAAGAGTCCWAAGTGTCTGATGTTTGTTCAGATTCGGGCTTCTGGACA

Fig. 1 Buffalo CATH4 full-spliced CDNA sequence. Exons 1 and 3 are underlined, and 2 and 4 are in bold. 3' Untranslated region is in italic. SNPs: $M(A / C), R(G / A), K(T / G), Y(C / T)$, and $W(T / A)$ 
cctctcgttggggcggtggtcactgtggcttctgctgctgggectagtggtaccctcggccagcgcccaggacctcag ctacagggaggccgtgcttcgtgctgtggatcagctcaatgagcggtcctcagaagctaatctctaccgcctcctgg wgctagacccrcctcycaaggatGTGAGTTGGGGAGGGGACTGY YCTAGGTGAGGGGCAGGG AGACAGATCAGAGAAGGAAAAATGAGCCTGAACCCAGTTTCCCCCGCACTTTAATCCGT CACCAGgatgcagatctgggcactcgaaagcctgtgagcttcacggtgaaggagactgtgtgccccaggacgac tcagcagccyrcggagcrgtgtgacttcaaggagaaagggGTGAGGCTGGGGGTTGGGGGTCAATG TTTCCY $\underline{\text { AGGGAGCTGAACAGGGAGCTTCTGGGA } \underline{W} G G T T T C C T G T C T C T G G G G T G A G G C}$ TGGGAGGTTATGGCCAAGGGGATTCCAGTTTGACCTTGAGCCTCTCCTTCCAGcgggtgaa rcagtgtgtggggacagtcaccctggacccgtccaatgaccagtttgacctaaactgtaatgmgGTGAGTGGT CCCTTCTGGACTGGGGGGTTTCTAGGGAAGATAGTGTGTGGAACATCCTTTGTACCAAT GACCCGCTGTCCCATCCAGGGCAGASAGAGGCCCTCCTACCCTGGCCCCTCCTTCCCTAA GCCCCAGGTCTCCAGCCCTGGGGCTGCCTCCCTTAGAGCAGTGGTCCTCTACTGGGGTTC CCATCTGGGAACTGACATGAGATGGATTCTCAGGACCCACTCGGACTTCCTGAATCTGA CWCTGGAGTGGGGCCCAGCCATTTGGATTTTCCCAAGACCTCCAGGGAATTGTGACTG* AGCTCAGCTTACGACACACTGACTGCAGTCGTGGGTTTTCAGCCTCTGCTCTCATCCAGC TTTGCTGGAATGTGCTTGTGACCCTGGGAAGCCCCATGCCATCTGTGGCCTCAGTTTTCC TGTCCGTCTGGGGTAGGGAATCAACCCCCCCTTTCCCAAAAAGG

Fig. 2 Buffalo CATH4 unspliced CDNA sequence. Starting position is c.21. Introns are in italic with the $5^{\prime}$ and $3^{\prime}$ splice site (GT-AG). Exons 1, 2 and 3 are in small letters. SNPs: $M(A / C), R(G / A), K(T / G), Y(C / T), S(G / C)$, and $W(T / A)$

a

Score Expect Identities Gaps Strand Frame 273 bits(302) 2e-77() 165/179(92\%) 0/179(0\%) Plus/Plus

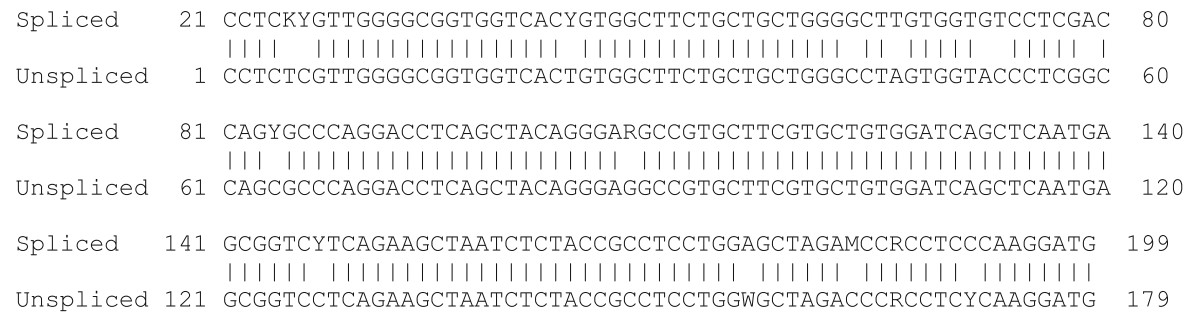

b

Score Expect Identities Gaps Strand Frame 183 bits(202) 3e-50() 107/108(99\%) 0/108(0\%) Plus/Plus

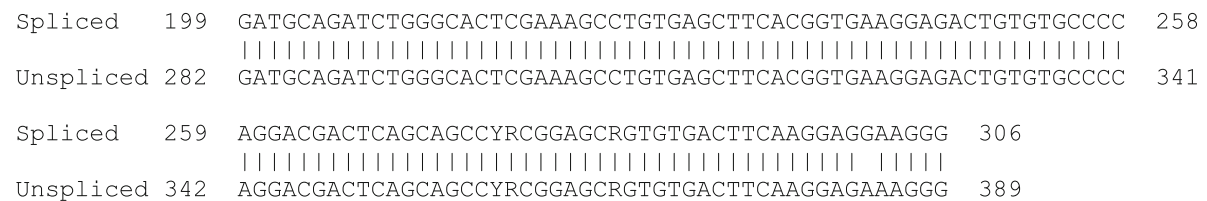

C

Score Expect Identities Gaps Strand Frame 127 bits(140) 2e-33() 72/73(99\%) 0/73(0\%) Plus/Plus

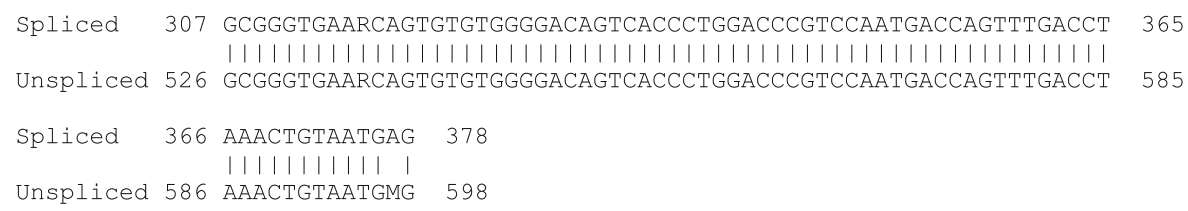

Fig. 3 Alignment between the spliced and unspliced CATH4 amplicons showing three separate matches which correspond to exons 1 (a), 2 (b), and 3 (c) 
were analyzed by multiple alignments using Clustal Omega (http://www.ebi.ac.uk/Tools/msa/clustalo/). Polymorphic sites were determined by visual examination of sequence's charts.

\section{Determining the four potential splice sites}

To predict the potential splice sites $5^{\prime}$ and 3' (GT/AG), the Splice Port tool (http://spliceport.cbcb.umd.edu/) was used. Prediction of the branch points (BPs) and

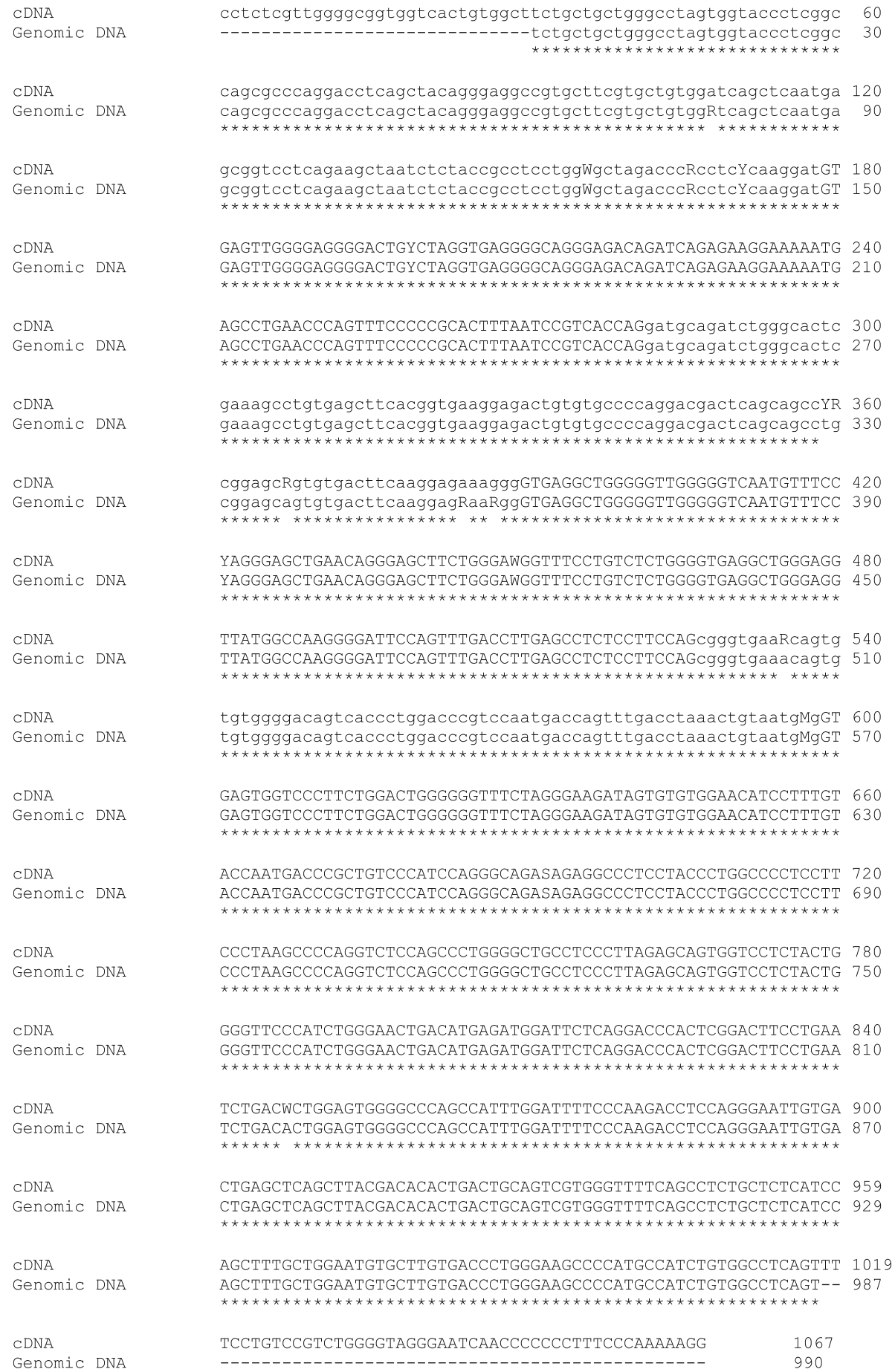

Fig. 4 Multiple sequence alignment of buffalo CATH4 genomic DNA and 1067 bp cDNA. Introns are in capital; exons 1, 2, and 3 are in small letters. SNPS: $M(A / C), R(G / A), K(T / G), Y(C / T), S(G / C)$, and $W(T / A)$ 
Table 2 The potential predicted 5' and 3' splice sites (GT-AG) in Buffalo CATH4 unspliced cDNA sequence

\begin{tabular}{|c|c|c|c|}
\hline \multicolumn{2}{|c|}{ Donor/acceptor splice site } & \multirow{2}{*}{$\begin{array}{l}\text { Short sequence } \\
\text { aggatGTgagtt }\end{array}$} & \multirow{2}{*}{$\begin{array}{l}\text { FGA score } \\
1.0048\end{array}$} \\
\hline Donor (c.198+g.1) & $5^{\prime}$ Intron 1 & & \\
\hline Acceptor (c.199-g.1) & 3' Intron 1 & tcaccAGgatgc & 0.5185 \\
\hline (Donor (c.306+g.1) & $5^{\prime}$ Intron 2 & aagggGTgagge & 0.8146 \\
\hline Acceptor (c.307-g.1) & $3^{\prime}$ Intron 2 & cttccAGcgggt & 0.7447 \\
\hline Donor (c.378+g.1) & $5^{\prime}$ Intron 3 & atgagGTgagtg & 1.5098 \\
\hline
\end{tabular}

Exonic region is in small letter, and intronic region in capital letter. FGA score indicates the SplicePort computational score

polypyrimidine tract (ppt) were carried out using SVMBP finder tool (http://regulatorygenomics.upf.edu/Software/SVM_BP/) (Corvelo et al. 2010).

\section{Results}

PCR was conducted on cDNA of buffalo. Only in three samples that the first primer pairs resulted in $526 \mathrm{bp}$ amplicon which corresponded to CATH4 full-spliced coding region with complete 4 exons and part of 3 ' untranslated region (Fig. 1). The second primer pair was used with the cDNA samples that were not amplified by the first primer. It amplified segments of $1067 \mathrm{bp}$ (Fig. 2). In the alignment between the two amplified amplicons, 526 bp (full-spliced segment) and $1067 \mathrm{bp}$ segments showed three separate matches (Fig. 3) covering exons1, 2, and 3. This left segments of $102 \mathrm{bp}$ between exons 1 and 2, 136 bp between exons 2 and 3, and 469 bp after exon 3 .

In order to determine the nature of the sequences between the exons and beyond, a PCR reaction was conducted using the second primer pair on genomic DNA buffalo sample. The resulted DNA amplicon was aligned with the cDNA (1067 bp segment) using
Clustal Omega (https://www.ebi.ac.uk/Tools/msa/clustalo/) (Fig. 4).

The alignment showed that the $1067 \mathrm{bp}$ cDNA (accession\# MK507762.1) is an intron-retained amplicon with full retention of intron 1 (102 bp) and intron 2 (136 bp) and a large segment of $5^{\prime}$ of intron 3 (469 bp). In order to find out reasons for unsplicing of the introns, the cDNA intron-retained sequence was analyzed. The analysis includes identifying the locations of any occurring SNPs and the sequences of cis-acting 4 splice signs, needed for splicing. The latter includes the $5^{\prime}$ (GT) and 3' (AG) intron splice sites, the branch points (BPs), and polypyrimidine tract $(\mathrm{ppt})$.

Prediction of the potential $5^{\prime}$ and $3^{\prime}$ splice sites (GTAG) in CATH4 mRNA intron-retained form was determined using the Splice Port tool (http://spliceport.cbcb. umd.edu/), and feature generation algorithm (FGA) scores were calculated (Table 2). The analysis showed that the donor splice sites in the three introns are the top splice site candidates which indicate that the three introns should have been spliced.

The potential branch points (BPs) and polypyrimidine tract (ppt) in introns 1 and 2 (intron 3 was only $5^{\prime}$ partial) of the intron-retained sequence were investigated using the SVM-BP finder (http://regulatorygenomics.upf. edu/Software/SVM_BP/).

The candid positions were the ones with svm_score of 1.3308 and 0.9529 located at distances of $35 \mathrm{nt}$ and $15 \mathrm{nt}$ from the 3 ' splice site of intron 1 and intron 2 , respectively, (Table 3).

Figure 5 shows all candidate branch points and polypyrimidine tract in intron 1 and intron 2 nucleotide sequences of the intron-retained cDNA. In intron 1 and intron 2, the uridine tracts had only 6 and 4 non-continuous uridines $(t)$, respectively.

Table 3 The potential predicted branch point (BP) and polypyrimidine tract (ppt) in buffalo CATH4 unspliced cDNA sequence

\begin{tabular}{llllllllll}
\hline seq_id & agez & ss_dist & bp_seq & bp_scr & y_cont & ppt_off & ppt_len & ppt_scr & svm_scr \\
\hline Intron 1 & 28 & 75 & aggtgaggg & -1.5456 & 0.41 & 42 & 20 & 30 & -2.5503 \\
Intron 1 & 28 & 56 & agatcagag & -3.8131 & 0.49 & 23 & 20 & 30 & -2.1565 \\
Intron 1 & 28 & 41 & aaatgagcc & -0.2929 & 0.67 & 8 & 20 & 30 & 0.2686 \\
Intron 1 & 28 & 35 & gcctgaacc & 1.3833 & 0.70 & 2 & 20 & 30 & 1.3308 \\
Intron 2 & 13 & 115 & gggtcaatg & -1.7699 & 0.50 & 40 & 12 & 27 & -2.5034 \\
Intron 2 & 13 & 96 & agctgaaca & 0.3411 & 0.51 & 21 & 12 & 27 & -0.4227 \\
Intron 2 & 13 & 57 & gggtgaggc & -0.4101 & 0.52 & 44 & 9 & 22 & -2.2737 \\
Intron 2 & 13 & 44 & aggttatgg & -2.4447 & 0.59 & 31 & 9 & 22 & -2.1868 \\
Intron 2 & 13 & 21 & gtttgacct & 1.4336 & 0.81 & 8 & 9 & 22 & 0.9218 \\
Intron 2 & 13 & 15 & ccttgagcc & 0.4239 & 0.90 & 2 & 9 & 22 & 0.9529 \\
\hline
\end{tabular}

seq_id - Sequence Identifier, agez AG dinucleotide exclusion zone length, ss_dist distance to 3 ' splice site, $b p \_s e q$ branch point sequence (nonamer; from -5 to +3 relative to the BP adenine), $b p_{-} s c r$ BP sequence score using a variable order Markov model, $y_{-}$cont pyrimidine content between the BP adenine and the $3^{\prime}$ splice site, ppt_off polypyrimidine tract offset relative to the BP adenine, ppt_len polypyrimidine tract length, ppt_scr polypyrimidine tract score, svm_scr final BP score using the SVM classifier 


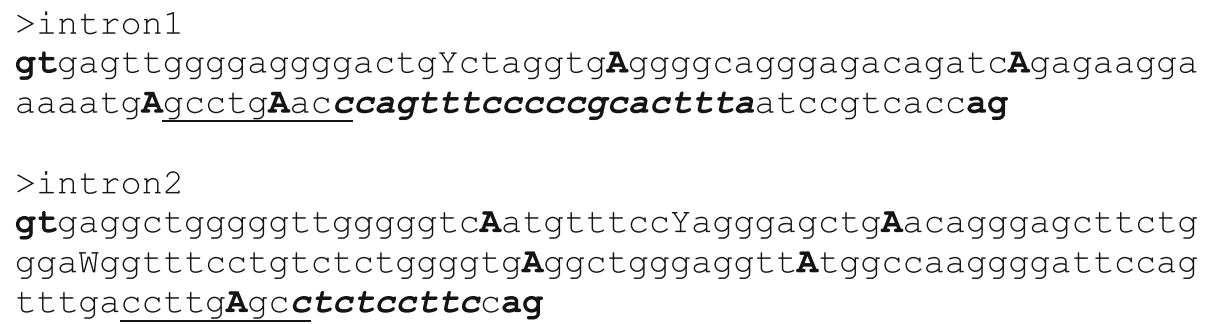

Fig. 5 SVM-BP finder outputs all candidate branch points (BPs) of Egyptian buffalo CATH4 intron-retained cDNA. Where BP adenine (A) are in capital letters, BP sequence (nonamer; from -5 to +3 relative to the BP adenine) are underlined, and polypyrimidine tract length (ppt_len) are in italic

\section{SNPs positions relative to splicing sites}

Polymorphic sites and their distances from the GT splice site were determined (Table 4) in nucleotide sequences of the spliced cDNA (8 SNPs) and the intron-retained cDNA (13 SNPs; 8 in exonic regions and 5 in intronretained segments).

\section{Discussion}

Intron retention, a form of alternative splicing that affects the mechanism of gene expression control in mammals, is not fully yet studied. It enhances gene regulatory complexity in vertebrates (Schmitz et al. 2017) and plays an essential conserved role in normal physiology and in diverse diseases (Wong et al. 2016). It was in 1997 that Coolidge et al. reported the role of the cis-regulatory elements in intron retention. Galante et al. (2004) and Sakabe and de Souza (2007) reported that retained introns are on the average shorter, more $\mathrm{C} / \mathrm{G}$ rich, and associated with weaker splice sites than constitutive introns.

In the present work, we have detected retention of the three introns in CATH4 of Egyptian buffalo. Accurate intron splicing occurs in the presence of strong cis-acting 4 splice signs which include the $5^{\prime}$

Table 4 Single-nucleotide polymorphisms in spliced and Intron-retained sequences of Egyptian buffalo CATH4 mRNA and their distances from GT splice site

\begin{tabular}{|c|c|c|c|}
\hline \multirow[t]{2}{*}{ Regions } & \multicolumn{2}{|c|}{ Positions of single-nucleotide polymorphisms } & \multirow[t]{2}{*}{ Distance from GT splice site } \\
\hline & Full-spliced cDNA & Intron-retained cDNA & \\
\hline \multirow[t]{10}{*}{ Exon 1(c.1-198) } & c. $25 \mathrm{~T} / \mathrm{G}(\mathrm{K})$ & C & 173 \\
\hline & c.26T/C(Y) & $\mathrm{T}$ & 172 \\
\hline & C. $44 \mathrm{~T} / \mathrm{C}(\mathrm{Y})$ & $\mathrm{T}$ & 154 \\
\hline & $c .84 \mathrm{~T} / \mathrm{C}(\mathrm{Y})$ & C & 114 \\
\hline & c.108G/A(R) & G & 90 \\
\hline & C.147C/T(Y) & C & 51 \\
\hline & c. $176 \mathrm{~A}$ & c. $176 \mathrm{~T} / \mathrm{A}(\mathrm{W})$ & 22 \\
\hline & c.183A/C(M) & $\mathrm{C}$ & 15 \\
\hline & c.186G/A (R) & c. $186 \mathrm{~A} / \mathrm{G}(\mathrm{R})$ & 12 \\
\hline & c.191C & c. $191 \mathrm{~T} / \mathrm{C}(\mathrm{Y})$ & 7 \\
\hline Retained intron 1 & - & C.198+21 C/T(Y) & 18 \\
\hline \multirow[t]{3}{*}{ Exon 2 (c.199-306) } & $\mathrm{c} 276 \mathrm{C} / \mathrm{T}(\mathrm{Y})$ & c.276 T/C(Y) & 30 \\
\hline & $c 277 A / G(R)$ & $c .277 \mathrm{G} / \mathrm{A}(\mathrm{R})$ & 29 \\
\hline & $\mathrm{c} 284 \mathrm{G} / \mathrm{A}(\mathrm{R})$ & c. $284 \mathrm{~A} / \mathrm{G}(\mathrm{R}) 4$ & 22 \\
\hline \multirow[t]{2}{*}{ Retained intron 2} & - & c.306+32 T/C(Y) & 29 \\
\hline & - & c.306+60 A/T(W) & 57 \\
\hline \multirow[t]{2}{*}{ Exon 3 (307-378) } & c.315G/ A (R) & c.315 G/A(R) & 63 \\
\hline & C.377A & C.377 C/A(M) & 1 \\
\hline \multirow[t]{2}{*}{ Retained intron 3} & - & c.378+94 G/C(S) & 91 \\
\hline & - & c.378+249T/A(W) & 246 \\
\hline
\end{tabular}


(GT) and 3' (AG) intron splice sites, the branch points (BPs), and polypyrimidine tract (ppt) sequences which are essential for accurate splicing (Black 2003). However, these cis-sequences provide only one half of the information required for recognition by the splicing machinery (Lim and Burge 2001). The number of nucleotides between the branchpoint and the nearest $3^{\prime}$ acceptor site, ranging from 18 to $40 \mathrm{bp}$, was found to affect splice site selection (Taggart et al. 2012; Clancy 2008). In the present study, the branch sites in the intron-retained cDNA were located at distances of $35 \mathrm{nt}$ and $15 \mathrm{nt}$ from the $3^{\prime}$ splice site for introns 1 and 2 , respectively, which are within the distances suggested by Clancy (2008). No information was available for intron 3 since it was only $5^{\prime}$ partially retained.

For intron-splicing, pyrimidine tracts play a role. Strong pyrimidine tracts contain 11 continuous uridines, whereas decreasing the continuous uridine stretch to five or six residues requires that the tract be located immediately adjacent to the AG for optimal competitive efficiency (Coolidge et al. 1997). In the present investigation, intron retention may have been caused by the presence of weak pyrimidine tracts which contained only 6 and 4 non-continuous uridine stretch for intron 1 and intron 2, respectively, and are not immediately next to AG. No results were available for intron 3 since only the $5^{\prime}$ segment of intron 3 was present in the sequence. It is worth mentioning that the fully retained introns in buffalo CATH4 gene were short. Retaining introns in genes with short introns have been reported (Sakabe and de Souza 2007).

Recently, SNPs have been considered to play a role in alternative splicing leading to intron retention (Wang et al. 2014; Ju et al. 2015). Exonic SNPs have direct effects on the properties of proteins, while SNPs within introns and untranslated region can affect the expression and splicing of mRNA (Wang et al. 2013, 2014). In a study by Estivill (2015), it was reported that 20,000 SNPs were located close to splice sites. However, there were cases where SNPs were $>30$ nucleotides away from the splice sites that disrupted splicing in 10,000 exons with evidence of alternative splicing and that splicing mutations located deeper in intronic regions (within 300 nucleotides from splice sites) were associated with disease. In the present study, 8 SNPs were detected in buffalo intron-retained cDNA, located at distances ranging from 7 to 246 nt away from the GT splice site which may be related to the retention of the three introns.

The presence of different CATH4 variants has been reported in other breeds of Indian buffaloes (Brahma et al. 2015). Individual buffalo from Mehsana and Murrah breeds was reported to carry 4-6 variants of CATH4 gene and that the gene could be present in multiple copies. Differences in CATH4 copy number has been reported to be breed-specific in indicine (Nelore) relative to the taurine cattle (Bickhart et al. 2012).

\section{Conclusion}

CATH4 in river buffalo (Egyptian breed) mRNA is present in spliced variant and intron-retained variants (three introns were retained) despite the presence of the conserved cis-sequences (the 4 splice signals) essential for accurate splicing. Retention of introns 1, 2, and 3 may have occurred as a result of short introns, weak polypyrimidine tracts containing 6 and 4 non-continuous uridine stretch, and/or SNPs located close to AG splice site.

\section{Abbreviations}

BPs: Branch points; CATH4: Cathelicidin-4; CD46: Cluster of differentiation46; IR: Intron retention; NCF4: Bovine neutrophil cytosolic factor 4; nt: nucleotide; PCR: Polymerase chain reaction; ppt: Polypyrimidine tract; SNPs: Singlenucleotide polymorphisms

\section{Acknowledgements}

Not applicable

\section{Authors' contributions}

AAAM and SMEN, designed the experiment, analyzed the data, and wrote the manuscript. EAB and ETS conducted the practical section of the work. NMO carried out the statistical analysis. All authors read and approved the final manuscript.

\section{Funding}

No specific fund was supplied for this work.

\section{Availability of data and materials}

We declare that all data analyzed during this study are included in this published article.

\section{Ethics approval and consent to participate}

Blood samples used in this study was collected and provided by the buffalo farm experienced veterinary.

Consent for publication

Not applicable

\section{Competing interests}

The authors declare that they have no competing interests.

Received: 13 March 2019 Accepted: 3 July 2019

Published online: 23 July 2019

\section{References}

Altschul SF, Gish W, Miller W, Myers EW, Lipman DJ (1990) Basic local alignment search tool. J Mol Biol. 215:403-410

Ausubel FM, Brent R, Kingston RE, Moore DD, Seidman JG, Smith JA, Struhl K (1990) Current protocols in molecular biology (editors). Greene Publishing and Wiley-Interscience, New York

Bickhart DM, Hou Y, Schroeder SG, Alkan C, Cardone MF, Matukumalli LK et al (2012) Copy number variation of individual cattle genomes using nextgeneration sequencing. Genome Res. 22:778-790

Black DL (2003) Mechanisms of alternative pre-mRNA splicing. Annu Rev Biochem. 27:291-336

Brahma B, Patra MC, Karri S, Chopra M, Mishra P et al (2015) Diversity, antimicrobial action and structure-activity relationship of buffalo cathelicidins. PLOS ONE. 10(12):e0144741

Chacko E, Ranganathan S (2009) Genome-wide analysis of alternative splicing in cow: implications in bovine as a model for human diseases. BMC Genomics. 10(Suppl3):S11 
Clancy S (2008) RNA splicing: introns, exons and spliceosome. Nat Educ. 1(1):31

Coolidge CJ, Seely RJ, Patton JG (1997) Functional analysis of the polypyrimidine tract in pre-mRNA splicing. Nucleic Acids Res. 25(4):888-896

Corvelo A, Hallegger M, Smith CW, Eyras E (2010) Genome-wide association between branch point properties and alternative splicing. PLoS Comput Biol. 6(11):e1001016

Das H, Sharma B, Kumar A (2006) Cloning and characterization of novel cathelicidin CDNA sequence of Bubalus bubalis homologous to Bos taurus cathelicidin-4. DNA Seq. 17(6):407-414

Dirksen WP, Sun Q, Rottman FM (1995) Multiple splicing signals control alternative intron retention of bovine growth hormone pre-mRNA. J Biol Chem. 270:5346-5352

Dorschner RA, Pestonjamasp VK, Tamakuwala S, Ohtake T, Rudisill J, Nizet V et a (2001) Cutaneous injury induces the release of cathelicidin anti-microbial peptides active against group A Streptococcus. J Investig Dermatol. 117:91-97

Drögemüller C, Reichart U, Seuberlich T, Oevermann A, Baumgartner M, Kühni Boghenbor K et al (2011) An unusual splice defect in the mitofusin 2 gene (MFN2) is associated with degenerative axonopathy in Tyrolean Grey cattle. PLoS One 6:e18931

Estivill X (2015) Genetic variation and alternative splicing. Nat Biotechnol. 33(4): $357-359$

FAO (2013) FAO Statistical year book - world food and agriculture

Galante PA, Sakabe NJ, Kirschbaum-Slager N, de Souza SJ (2004) Detection and evaluation of intron retention events in the human transcriptome. RNA. 10: 757-765

Gallo RL, Murakami M, Ohtake T, Zaiou M (2002) Biology and clinical relevance of naturally occurring antimicrobial peptides. J Allergy Clin Immunol. 110:823-831

Gillenwaters EN, Seabury CM, Elliott JS, Womack JE (2009) Sequence analysis and polymorphism discovery in 4 members of the bovine cathelicidin gene family. J Hered. 100(2):241-245

Ju Z, Wang C, Wang X, Yang C, Sun Y, Jiang Q et al (2015) Role of an SNP in alternative splicing of bovine NCF4 and mastitis susceptibility. PLOS ONE 10(11):e0143705

Lim LP, Burge CB (2001) A computational analysis of sequence features involved in recognition of short introns. Proc Natl Acad Sci USA. 98:11193-11198

Marai IFM, Habeeb AAM (2010) Buffaloes' reproductive and productive traits as affected by heat stress. Tropical Subtropical Agroecosystems. 12:193-217

Menoud A, Welle M, Tetens J, Lichtner P, Drögemüller C (2012) A COL7A1 mutation causes dystrophic epidermolysis bullosa in Rotes Höhenvieh cattle. PLoS One. 7:e38823

Miller SA, Dykes DD, Polesky HF (1988) A simple salting out procedure for extracting DNA from human nucleated cells. Nucleic Acids Res. 16:1215

Sakabe NJ, de Souza SJ (2007) Sequence features responsible for intron retention in human. BMC Genomics. 8:59

Schmitz U, Pinello N, Jia F, Alasmari S, Ritchie W, Keightley MC, Shini S, Lieschke GJ, Wong JJ, Rasko JEJ (2017) Intron retention enhances gene regulatory complexity in vertebrates. Genome Biol. 18:216

Taggart AJ, DeSimone AM, Shih JS, Filloux ME, Fairbrother WG (2012) Large-scale mapping of branchpoints in human pre-mRNA transcripts in vivo. Nat Struct Mol Biol. 19(7):719-721

Untergasser A, Cutcutache I, koressaar T, ye J, Faircloth BC, Remm M, Rozen SG (2012) Primer 3 new capabilities and interfaces. Nucleic Acids Res. 40:e115

Wang X, Li T, Zhao HB, Khatib H (2013) A mutation in the 3' untranslated region diminishes micro RNA binding and alters expression of the OLR1 gene. J Dairy Sci. 96:6525-6528

Wang X, Zhong J, Gao Y, Ju Z, Huang J (2014) A SNP in intron 8 of CD46 causes a novel transcript associated with mastitis in Holsteins. BMC Genomic. 15:630

Wong JJ, Au AY, Ritchie W, Rasko JE (2016) Intron retention in mRNA: no longer nonsense: known and putative roles of intron retention in normal and disease biology. Bioessays. 38(1):41-49

Zaiou M, Gallo RL (2002) Cathelicidins, essential gene-encoded mammalian antibiotics. J Mol Med. 80:549-561

Zanetti S, Deriu A, Volterra L, Falchi MP, Molicotti P, Fadda G, Sechi LA (2000) Virulence factors in Vibrio alginolyticus strains isolated from aquatic environments. Annali di Igiene. 12(6):487-491

\section{Publisher's Note}

Springer Nature remains neutral with regard to jurisdictional claims in published maps and institutional affiliations.

\section{Submit your manuscript to a SpringerOpen ${ }^{\circ}$ journal and benefit from:}

- Convenient online submission

- Rigorous peer review

- Open access: articles freely available online

- High visibility within the field

- Retaining the copyright to your article

Submit your next manuscript at $\boldsymbol{\nabla}$ springeropen.com 